\title{
A ESCRITA DE GUIMARÃES ROSA: UM COMPROMISSO DO CORAÇÃO
}

\section{THE WRITING OF GUIMARÃES ROSA: A COMMITMENT OF THE HEART}

\author{
Eduardo de Faria Coutinho ${ }^{l}$
}

\section{RESUMO}

Ao colocar em xeque a linguagem e a estrutura narrativa tradicional da literatura brasileira, através da ruptura de todo o convencional e das inovações que introduziu em seu processo de escrita, Guimarães Rosa realizou, com sua obra, uma verdadeira revolução no sistema literário nacional. Essa postura, que por um lado o aproximou da que fora adotada pelas Vanguardas do princípio do século XX e do Modernismo brasileiro da primeira fase, e, por outro, induziu críticos, particularmente euro-norte-americanos, a vê-lo como um "pós-moderno", será discutida neste trabalho, a partir de fragmentos extraídos de momentos distintos de sua narrativa, que teve como uma de suas mais fortes preocupações a de que é "somente renovando a língua é que se pode renovar o mundo".

PALAVAS-CHAVE: Guimarães Rosa; linguagem e estrutura narrativa; Vanguardas e Modernismo.

\footnotetext{
1 Professor Titular Emérito de Literatura Comparada da Universidade Federal do Rio de Janeiro (UFRJ). Mestre e Literatura Comparada pela Universidade da Carolina do Norte, Chapel Hill, e Doutor (PhD) em Literatura Comparada pela Universidade da Califórnia, Berkeley (1983). É pesquisador 1A do CNPq e sua principal área de pesquisa é a Literatura Comparada, com ênfase sobre a Literatura LatinoAmericana contemporânea.
} 


\section{ABSTRACT}

By questioning any sort of literary convention and by introducing a significant number of innovations into Brazilian literature's language and narrative structure, Guimarães Rosa accomplished in his works a real revolution of the national literary system. This attitude, on the one hand, has brought him closer to the early twentieth century Vanguards and to the first phase of the Brazilian Modernist movement, but, on the other hand, it has led several critics, particularly from Europe and the USA, to see him as a post-modern writer. In any case, however, it indicates a politico-philosophical position that can be represented by the author's own words who, in an interview by the critic Günter Lorenz, affirmed that "it is only by renewing language that one can renew the world". In this essay, we will present some of the main innovations introduced by the writer both in language and narrative structure, and will discuss the role they have had in his work as a whole and in the cadre of mid-twentieth century Brazilian literature.

KEYWORDS: Guimarães Rosa; language and narrative structure; Vanguards and Modernism.

Os ventos da inovação que começaram a soprar na Europa em finais do século XIX e varreram o cenário estético nas primeiras décadas do século XX sob a forma das Vanguardas - do Futurismo ao Surrealismo - tiveram no Brasil sua expressão no movimento modernista que, tendo-se preparado longos anos, eclodiu em 1922 em São Paulo no episódio conhecido como a Semana de Arte Moderna. Daí para a frente, não pararam mais de soprar, levando a literatura e as artes a transformações que, a despeito das diferenças presentes em cada contexto, mostraram-se muitas vezes radicais, máxime no que concerne a sua linguagem ou expressão. No caso do Brasil, onde ainda imperava o dilema, vivo desde os anos da colônia, entre a importação cega de modelos e a busca de constituição de algo novo, com um perfil próprio, a ruptura da linguagem que dominava a cena artística, calcada em moldes que deixava transparecer a todo instante vozes oriundas da metrópole, tornou-se uma bandeira do movimento, e revelou-se sob formas diversas, que vão do culto ao popular ("a língua . . . natural e neológica/ a contribuição milionária de todos os erros” - ANDRADE, O. In: TELES, 1977, p. 267) à forte elaboração de uma dicção como a de Guimarães Rosa, que mescla, sem abandono à tradição, o erudito e o popular, o cosmopolita e o regional, o arcaico e o neologismo.

Geralmente situado pela historiografia literária brasileira como autor da chamada Terceira Geração do Modernismo, que se caracterizou, entre outras coisas, por acentuada preocupação com os meios de expressão literária, com o sentido estético do texto, e por demonstrar, na maioria dos casos, profunda consciência do caráter de ficcionalidade da obra, de sua própria literariedade, Guimarães Rosa levou essa preocupação a tal ponto que efetuou em sua ficção verdadeira revolução da linguagem narrativa, erigindo-se como um marco na prosa literária brasileira do século XX. E, ao fazê-lo, ele não só deixou transparecer muitos dos ideais estéticos da Primeira Geração do Modernismo, a chamada "fase heroica", como também de algumas das Vanguardas europeias que, ao serem apropriadas, mesclaram-se com elementos locais, dando origem ao movimento. É assim que, ao tom coloquial de um Mário ou de um Oswald de Andrade, somou-se uma sintaxe de ruptura, por vezes telegráfica e de cunho eminentemente paradigmático, herdada de Vanguardas europeias como o Futurismo e o Dadaísmo. 
As relações do Modernismo com o Futurismo, bem como com o Dadaísmo, não foram das mais próximas, chegando muitas vezes os autores brasileiros a negar qualquer tipo de filiação, como é o caso de Mário de Andrade, que, ao ser chamado por seu parceiro intelecutal Oswald de "poeta futurista", reagiu com veemência, primeiro em artigo de jornal e depois no famoso "Prefácio Interessantíssimo" de seu livro Pauliceia desvairada. Mário não se queria futurista, pelo menos ao modo de Marinetti, mas advogou em grande escala as "palavras em liberdade", tão proclamadas por este em seu "Manifesto Técnico", e defendou em toda sua obra, principalmente poética, a destruição da sintaxe tradicional, em prol de uma distribuição dos substantivos "ao acaso, como nascem" (MARINETTI, "Manifesto Técnico", In: TELES, 1977, p. 89). No Brasil, o Futursimo não chegou a constituir-se como movimento, nem gerou a publicação de uma revista, como ocorreu em Portugal com a Portugal Futurista, mas suas marcas se fizeram sentir ao longo do Modernismo, em especial nos autores que se empenharam na tarefa de reestruturação da linguagem, e que reagiram com vigor a toda visão cristalizada de mundo.

Avesso a tudo o que se apresenta como fixo ou natural, cristalizado pelo hábito e instituído como verdade inquestionável, Guimarães Rosa empreende ao largo de toda sua travessia literária verdadeira cruzada em prol da reflexão, desencadeando, através da linguagem, um processo de desconstrução, que desvela constantemente sua própria condição de discurso e seu consequente caráter de provisoriedade. Esta reflexão é por certo uma das principais marcas de seu fazer artístico e um dos aspectos mais responsáveis pela unicidade de seu traço, que fazem do escritor um alquimista, ou, apesar de seus protestos ao termo, um grande "revolucionário da linguagem" (COUTINHO, 1991, p. 84). Além disso, ela traduz a ideia, expressa por ele próprio em entrevista a Günter Lorenz de que é missão do escritor explorar ao máximo todas as potencialidades do signo linguístico, porque "somente renovando a língua é que se pode renovar o mundo" (LORENZ, In: COUTINHO, 1973, p. 315-55).

Embotado por um cotidiano calcado na continuidade, que se expressa pela repetição mecânica de atos e gestos, o homem, e em particular o adulto comum, não percebe a automatização a que se sujeita, cumprindo o inexplicável sem nenhuma autonomia de raciocínio. Seu discurso, construído de antemão pela comunidade a que pertence, é incorporado por ele sem nenhuma indagação, e sua expressão se revela como a ratificação de uma prática tradicional, que se impõe inoxoravelmente, naturalizando o não naturalizável e camuflando consequentemente o seu caráter de construção. Esta linguagem, a que Guimarães Rosa designa de "linguagem corrente", expressa “apenas clichês e não ideias” (LORENZ, In: COUTINHO, 1991, p. 88), não se prestando à autonomia do raciocínio. Ela está morta, e, segundo ele, o que está morto não pode engendrar ideias. A fim de poder "engendrar ideias", é preciso romper com essa linguagem, desautomatizá-la. O idioma, para Rosa, "é a única porta para o infinito, mas infelizente está oculto sob montanhas de cinzas" (IBIDEM, p. 83). Por isso, é necessário depurá-lo, revitalizálo, violando constantemente a norma e substituindo o lugar-comum pelo único, a fim de que 
ele possa recobrar sua poiesis originária e atingir o outro de maneira eficaz. É com esse intuito que ele se entrega de corpo e alma à tarefa de revitalização da linguagem, e que a vê como um “compromisso do coração" (IBIDEM, p. 84).

O processo de revitalização da linguagem empreendido por Guimarães Rosa baseia-se fundamentalmente na utilização do recurso do estranhamento (a ostranienie, dos formalistas russos), com a consequente eliminação de toda conotação desgastada pelo uso, e na exploração das potencialidades da linguagem, da face oculta do signo, ou, para empregar palavras do próprio autor, do "ileso gume do vocábulo pouco visto e menos ainda ouvido, raramente usado, melhor fora se jamais usado" (ROSA, 1970, p. 238). Os procedimentos para ocasionar o estranhamento são, contudo, numerosos e distintos, estendendo-se desde o plano da língua stricto sensu ao do discurso narrativo, e chegando em alguns casos a constituir o eixo-motor de todo o texto. No primeiro caso, citem-se a título de amostragem a desautomatização de palavras que haviam perdido sua energia original e adquirido sentidos fixos, associados a um contexto específico (palavras como "sertão" no romance regionalista brasileiro, por exemplo); de expressões que se haviam tornado vagas e enfraquecidas, encobertas com significações que escondiam seu viço originário; e da sintaxe como um todo que havia abandonado suas múltiplas possibilidades e se limitara a clichês e estereótipos. E, no segundo caso (o do discurso narrativo), mencionem-se, entre um vasto leque de recursos, a ruptura da linearidade tradicional e das relações de causa e efeito na narrativa, que cedem lugar à simultaneidade e à multiplicidade de planos espaciais; e finalmente a presença constante da metalinguagem, que sinaliza a todo instante o caráter de construção do discurso (COUTINHO, 1993, p. 31-48).

Como é numeroso o uso desses procedimentos no texto de Guimarães Rosa, nos limitaremos aqui a mencionar alguns dos mais frequentes, e começaremos então, no plano vocabular, pela afixação e a aglutinação. A primeira consiste no acréscimo, feito ao "significante" de um vocábulo, de um ou mais afixos que venham a alterar seu significado, sugerindo novas conotações. É o que ocorre, por exemplo, com a palavra "sozinhozinho", empregada no Grande sertão: veredas. A palavra "só", exclusivamente conceitural em português, não contém em si mesma nenhuma conotação emocional. O poeta anônimo, ao sentir que o vocábulo era insuficiente para expressar sua solidão, decidiu acrescentar-lhe um sufixo diminutivo "-inho", "-zinho", bastante usado na língua com o sentido de intensidade (cf. "cedinho", "devagarzinho"). E o resultado foi a palavra "sozinho", significando "muito só". Entretanto, com o desenvolvimento da língua, "sozinho" veio a perder seu significado poético e passou a ser usado como um simples sinônimo de "só". Guimarães Rosa, percebendo a inexpressividade do vocábulo, procurou reavivar o seu significado originário, servindo-se do mesmo processo que acreditava tivesse sido utilizado um dia. Assim, repetiu o sufixo diminutivo no final e criou a forma "sozinhozinho".

A aglutinação, o segundo procedimento mencionado, consiste na combinação dos "significantes" de dois ou mais vocábulos, de tal modo que o neologismo criado contenha os significados de todos eles. Estes neologismos, chamados palavras portmanteau, são 
particularmente abundantes em toda a obra do autor. Por exemplo, "nenhão", fusão do pronome indefinido "nenhum" e do advérbio de negação "não"; "fechabrir", conciliação dos opostos "fechar" e "abrir"; "prostitutriz", combinação dos sinônimos "prostituta" e "meretriz"; ou ainda as formas "sussurruído" e "adormorrer", empregadas para sugerir respectivamente o cochicho de um grupo de pessoas num velório e a morte de um indivíduo como uma espécie de sono.

Este processo de alteração do "significante" não se restringe, ademais, ao nível puramente vocabular. Sintagmas e às vezes sentenças inteiras, que se haviam tornado clichês, são frequentemente alterados pelo autor com o objetivo de fazê-los recobrar sua expressividade originária. Assim, sintagmas como "nu da cintura para cima" ou "não sabiam de coisíssima nenhuma" transformam-se em Grande sertão: veredas em "nu da cintura para os queixos" e "não sabiam de nada coisíssima". Quando um falante de português escuta a expressão "nu da cintura para cima" ou a sentença "não sabiam de coisíssima nenhuma", não pensa sobre as diversas nuances de significado que elas contêm. Na verdade, não chega nem a notar o uso peculiar do sufixo superlativo "-íssimo", próprio de um adjetivo, aplicado ao substantivo "coisa". Estes sintagmas se acham tão bem integrados em sua língua, e foram de tal modo desgastados pelo uso, que não sugerem para ele nenhuma conotação especial. Todavia, quando escuta a expressão "nu da cintura para os queixos" ou a sentença "não sabiam de nada coisíssima", a estranheza das construções fere sua percepção e força-o a refletir sobre o significado delas. E, ao fazê-lo, ele é levado a enxergar além do puro aspecto denotativo da expressão.

Mas é no campo da sintaxe, ao contrário do que se supõe normalmente, que residem as maiores inovações de Guimarães Rosa com relação à linguagem literária em seu sentido estrito: trata-se de uma sintaxe com uma lógica bastante peculiar e marcada por uma estrutura compacta, telegráfica. Dada, contudo, a complexidade do tópico, que nos impede que o abordemos com algum vagar neste texto, optamos apenas pela simples menção a alguns dos processos mais frequentes empregados pelo autor. Citem-se, assim, a enumeração de palavras pertencentes à mesma classe gramatical e ao mesmo campo semântico, que introduz uma ruptura na estrutura sintagmática do discurso e contribui para uma espécie de neutralização da oposição entre prosa e poesia (os nomes de plantas e animais, por exemplo, e a enumeração dos combatentes antes das batalhas, que nos reportam às epopeias clássicas); a inversão da ordem tradicional dos vocábulos e sintagmas na oração, que constitui talvez o traço mais erudito de seu estilo e o responsável, em grande parte, pelo rótulo que lhe quiseram emprestar de neo-barroco; e finalmente o uso de orações justapostas e construções elípticas, típicas da linguagem oral, que revelam uma preferência acentuada pela coordenação sobre a subordinação, e por um tipo de estilo fluido, linear e direto.

No plano lato sensu do discurso narrativo, muitas foram as inovações introduzidas por Guimarães Rosa em sua busca de uma nova expressão. E, em todos os casos, o procedimento foi o mesmo: a eliminação dos elementos gastos (excessos descritivos, abundância de pormenores irrelevantes, uso de recursos cristalizados) e a exploração das potencialidades do discurso. Aqui, no entanto, devido à amplitude e complexidade do assunto, nos limitaremos 
a assinalar alguns dos recursos de maior relevância, presentes no Grande sertão: veredas: a substituição da linearidade cronológica tradicional pela concentração em dois estratos temporais que se imbricam e prolongam como num eterno presente; o abandono do sentido unidimensional do espaço em nome da simultaneidade e multiplicidade de planos; o uso de um ponto de vista centrado em um protagonista essencialmente ambíguo, que habita dois mundos de ordem distinta (um mítico-sacral e um lógico-racional) e que, como tal, contribui para manter a ambiguidade da narrativa; o emprego de uma técnica híbrida de monólogo-diálogo, que funde a estrutura própria do diálogo e a ênfase sobre a perspectiva de um só indivíduo, característica do monólogo; a fusão dos gêneros tradicionais épico, lírico e dramático, que convergem na narrativa num todo globalizante, questionando a própria exclusividade de cada um deles; e a co-existência de uma linguagem-objeto e de uma metalinguagem, na medida em que o narrador põe em xeque a todo instante a própria técnica de narrar e que sinaliza a todo momento o caráter de construção do discurso (COUTINHO, 1993, p. 31-48). A obra de Guimarães Rosa é não só um percuciente labor de ourivesaria, que desconstroi e reconstroi o signo a cada momento, mas também uma reflexão aguda sobre a própria linguagem, que se erige frequentemente como tema de suas estórias. Como é esta reflexão aguda sobre a própria linguagem que irá atuar principalmente sobre o leitor, iluminando a sua percepção, trataremos a seguir de alguns exemplos de narrativas em que a linguagem se constitui como tema, levando o personagem, e consequentemente o leitor a verdadeiras revelações.

O primeiro caso é o conto "São Marcos", de Sagarana, em que o protagonista é salvo de uma cegueira súbita e inexplicável ao tomar consciência do sentido de uma reza. "São Marcos" é a estória de um rapaz que habitava um vilarejo dominado pela prática da feitiçaria. Este rapaz, que se diferençava de seus companheiros porque não acreditava em poderes sobrenaturais e chegava a fazer troça das orações que se rezavam como proteção contra o mal, costumava dar longas caminhadas pelo mato com o propósito de observar as plantas e a vida dos animais. Entretanto, no caminho que dava para a mata, ficava a casa de um feiticeiro, e todas as vezes que ele passava por ali, divertia-se com a figura do homem. Certo dia, ele se excedeu e conseguiu aborrecer o feiticeiro. Prosseguindo seu caminho, encontrou um amigo, de quem ouviu a estória de um homem, fugido da prisão graças a uma oração mágica, mas não deu grande importância ao episódio. O protagonista alcançou a mata e penetrou-a conforme o costume. No entanto, após breve estada por entre as árvores, achou-se de súbito completamente cego. Neste momento, a percepção visual que o personagem tinha da mata foi substituída por uma percepção auditiva, e ele começou a escutar ruídos de todos os tipos, culminando com a voz do amigo. Esta voz foi associada em sua mente à estória ouvida poucos minutos antes, e ele instintivamente começou a dizer a reza mágica. As palavras da oração exerceram sobre o protagonista o efeito de uma revelação, e ele tomou consciência da causa de sua cegueira. Correu então para a casa do feiticeiro e, após luta corporal, recobrou a visão. 
Nesta estória, que constitui uma das primeiras teorizações de Guimarães Rosa a respeito da linguagem, o personagem se salva graças exatamente à sua capacidade de desautomatização do discurso, ao seu veio criativo, poético, expresso por exemplo quando ele avista nuns bambus os nomes de uns reis leoninos que ele mesmo havia escrito, e pára, comentando com emoção:

E era para mim um poema esse rol de reis leoninos, agora despojados da vontade sanhuda e só representados na poesia. Não pelos cilindros de ouro e pedras, postos sobre as reais comas riçadas, nem pelas alargadas barbas, entremeadas de fios de ouro. Só, só por causa dos nomes. (ROSA, 1970, p. 215)

O personagem tornara-se misteriosamente cego, e não conseguia encontrar uma explicação racional para o que lhe sucedera. Então começou a dizer a oração. Mas como não acreditava em poderes sobrenaturais, a reza não fazia nenhum sentido para ele; era simples repetição mecânica. Naquele momento, porém, decidiu refletir sobre o seu significado, decidiu explorar o "ileso gume" dos vocábulos, e foi capaz de enxergar além do aparente. As palavras revelaramlhe a causa de sua cegueira e a maneira de encontrar a cura:

E, pronto, sem pensar, entrei a bramir a reza-brava de São Marcos. Minha voz mudou de som, lembro-me, ao proferir as palavras, as blasfêmias, que eu sabia de cor. Subiu-me uma vontade louca de derrubar, de esmagar, destruir... E então foi só doideira e a zoeira, unidas a um pavor crescente. Corri. (IBIDEM, p. 253)

Em outra narrativa, desta vez de Primeiras estórias - "Famigerado" -, a salvação do protagonista é garantida pela manipulação que faz do signo linguístico. Aqui, o relato todo gira em torno do significado do vocábulo que lhe dá título. Um jagunço, afamado na região pelos crimes cometidos fora chamado de "famigerado" por um moço do governo, e viaja até um vilarejo para consultar um médico culto sobre o significado da palavra. Este último, ao perceber o risco, deixou de lado a conotação negativa que o termo havia adquirido, e escudou-se primeiro em seu sentido denotativo - "Famigerado é inóxio, é "célebre", "notório", "notável" (ROSA, 1978, p. 11) -, e em seguida na exploração de seus aspectos positivos: - Famigerado? Bem. É: “importante”, que merece louvor, respeito...”(IBIDEM, p. 11). E, preocupado ainda com a desconfiança do outro, que lhe pede para traduzir "em fala de pobre, linguagem de em dia-de-semana", complementa: "Olhe: eu, como o sr. me vê, com vantagens, hum, o que eu queria uma hora destas era ser famigerado-bem famigerado, o mais que pudesse! ...” (IBIDEM, p. 11), deixando assim o jagunço satisfeito e salvando-se de possíveis embaraços. Altamente representativa do processo de revitalização da linguagem levado a cabo por Guimarães Rosa, a estorinha se calca exatamente na desconstrução de um significado cristalizado e na exploração das potencialidades do signo. O significado pejorativo, primeiro a emergir no uso do termo, é despojado de qualquer sentido homogêneo, e revelado como mais um na rede de possíveis significações que aquele possa propiciar. O usuário, então, já livre das malhas que o prendiam, passa a explorar seu potencial, utilizando-o poeticamente, ou mesmo conscientemente para o seu próprio benefício. O resultado é que o vocábulo, que em seu sentido desgastado poderia 
ocasionar uma tragédia, muda, por sua desautomatização, o rumo dos acontecimentos, desmascarando em conseqüência, o cunho ideológico da linguagem.

Um terceiro e último relato, finalmente, que não pode faltar à nossa reflexão, é a novela "O recado do morro", de Corpo de baile, que o próprio Rosa resumiu para seu tradutor italiano Edoardo Bizzarri como "a estória de uma canção a formar-se. Uma 'revelação', captada, não pelo interessado e destinatário, mas por um marginal da razão, e veiculada e aumentada por outros seres não-reflexivos, não escravos ainda do intelecto: um menino, dois fracos de mente, dois alucinados - e, enfim, por um ARTISTA; que, na síntese artística, plasma-a em CANÇÃO, do mesmo modo perfazendo, plena, a revelação inicial”(ROSA, 1980, p. 59). “O recado do morro" é a estória de um rapaz ingênuo, vaidoso, e odiado por muitos, dentre os quais supostos amigos, por causa de seu jeito conquistador, que é por estes atraído para uma cilada, salvandose, no final, graças a uma revelação, ocasionada pelas palavras de uma canção popular, que se formou a partir de fragmentos lançados por um louco e transmitidos através de uma cadeia de seres à margem do senso comum. Marcada por uma série de encontros inesperados ocorridos ao longo de uma expedição científica, de que participam o protagonista e seu traidor, a narrativa tem como eixo a transmissão de um recado - o aviso da traição -, que só atinge o destinatário quando transformado em canção, em obra de arte. Os germes iniciais da canção, o início da frase, para usar a expressão do próprio Rosa, surgem da percepção de um louco sob a forma do ruído de um morro, que ele teria interpretado como mensagem, e a partir daí se propagam, construindose esta gradativamente e ao mesmo tempo que a narrativa. No final, contudo, ainda que pronta, e lançada a público ao som do violão do poeta, ela só atinge o protagonista quando este, depois de repeti-la mecanicamente por algum tempo, começa a atentar para o sentido de suas palavras.

Texto fundamental na composição da ars poetica rosiana, "O recado do morro" é uma bela metáfora de sua criação artística, que começa num processo de revelação e completa-se originando outro, instalando consequentemente uma cadeia que não tem mais fim, e desdobrando-se como constante reescritura, como sucessivas traduções. Enquanto revelação, ele se faz no plano da intuição, no desvão da lógica racionalista, no palco do transcendente: é um louco que capta o recado do morro e o transmite a outros excluídos, a outros seres que, por se terem mantido à margem do senso prático, do absurdo da lógica racionalista, são dotados da capacidade de enxergar mais longe, de perceber o que o cotidiano encobre com camadas de cinzas. E como o louco, as crianças e os velhos, nesse rondó de marginalizados, que, como Nhinhinha, de "A menina de lá" ou Rosalina, de "A estória de Lélio e Lina”, percebem o óbvio não-dito -"Tatu não vê a lua"(ROSA, 1978, p. 17), diz a primeira com argúcia; ou "Um dia você vai ver, meu Mocinho: coração não envelhece, só vai ficando estorvado... Como o ipê: volta a flor antes da folha...”(ROSA, 1965, p. 182), diz a segunda, com doçura -, finalmente o poeta, que dá forma às partículas, decodifica, traduz mensagens, e abre espaços para outros, leitores, tradutores, também poetas, recriadores, que, como o Laudelim, contador de estórias, de/re/codifica o recado do morro, transmitindo-o como canção ao protagonista. Não esqueçamos, no entanto, que a revelação final só se dará, de 
fato, na instância da recepção, quando as palavras da canção são digeridas por este. $\mathrm{O}$ autor, homem comum, visionário porque atento, produz o recorte poético, mas a planta só viceja verdadeiramente quando o protagonista a traduz, esmerilhando seus sentidos e acrescentando sua leitura.

Com a renovação constantemente empreendida do dictum poético, através da desestruturação de todo o petrificado, Guimarães Rosa instaura em suas páginas um verdadeiro laboratório de reflexão, que se estende dos próprios personagens ao leitor, reativando o circuito discursivo e transformando o último de mero consumidor num participante ativo do processo criador. Ciente do fato, como ele mesmo afirma, através das palavras do narrador de Grande sertão: veredas, de que "toda ação principia mesmo é por uma palavra pensada. Palavra pegante, dada ou guardada, que vai rompendo rumo" (ROSA, 1958, p. 170), ele fornece ao leitor esta "palavra", por meio das inovações que introduz, e, ao estimular sua reflexão e conseqüente participação na construção da própria obra, faz dele um grande questionador, um desbravador de caminhos. Assim como os personagens de Guimarães Rosa estão freqüentemente se indagando sobre o sentido das coisas e muitas vezes pondo em xeque seus próprios atos e visão de mundo - Riobaldo é talvez o mais perfeito exemplo dessa atitude - o leitor, para ele, é sempre um perseguidor, um indivíduo marcado pelo signo da busca, imerso, como todos os seres, numa longa travessia, cujo sentido último jamais é alcançado. Não é sem razão que a narrativa do Grande sertão: veredas, não só para ficarmos com o mesmo exemplo, mas também por ser ela, por certo, paradigmática de toda a obra do autor, se abre e fecha com uma pergunta para a qual não há resposta única ou definitiva: “o diabo existe? " Tal qual seu narrador, que conclui o relato - já feito antes ao seu Compadre Quelemém, e agora a um interlocutor urbano e culto - reintroduzindo a dúvida que desde o início o atormentava, o leitor rosiano encerra suas aventuras pelos fios do texto levantando "outras, maiores perguntas", e configurando-se como elo de uma cadeia que se projeta para além das páginas do livro.

Tomando por base este último aspecto, que constitui a nosso ver uma das mais importantes inovações introduzidas por Guimarães Rosa no nível do discurso narrativo - a estrutura de pergunta com que se constroi o Grande sertão: veredas, - passaremos uma vista sobre a estrutura desta obra e veremos como se verifica no romance o processo de representação da realidade. E para isso começaremos lembrando que a narrativa do romance se constroi em torno de duas linhas associadas a dois momentos distintos da vida do protagonista-narrador e marcadas por duas atitudes diferentes de sua parte, que já aparecem indicadas no seguinte trecho:

De primeiro eu fazia e mexia, e pensar não pensava. Não possuía os prazos. Vivi puxando dificil de difícel, peixe vivo no moquém; quem moi no aspro não fantaseia. Mas agora, feita a folga que me vem, e sem pequenos dessossegos, estou de range-rede. (IBIDEM, p. 11)

Assim, de um lado temos um tempo passado em que o personagem vivenciou os fatos narrados agora, predominantemente marcado pela sua ação no sertão; e de outro um tempo presente, caracterizado por uma atitude especulativa, em que ele relata estes eventos a um interlocutor e os revive no próprio ato da narração. 
Estas duas linhas, embora de natureza distinta, interpenetram-se a todo instante na narrativa e é da dependência mútua estabelecida entre elas que se desenvolve a tensão de toda a narração. Riobaldo, o protagonista-narrador, vivera uma série de experiências no passado que permanecem ainda vivas sob a forma de indagações atormentadoras, e ao relatar sua história ao interlocutor, ele o faz com o objetivo primordial de dissipar o estado de incerteza gerado por essas indagações. Daí a presença de afirmações como a seguinte, repetida constantemente através da narrativa: "Conto ao senhor é o que eu sei e o senhor não sabe, mas principal quero contar é o que eu não sei se sei, e que pode ser que o senhor saiba" (IBIDEM, p. 217); daí também a necessidade que o narrador expressa de reconstituir o passado exatamete como teria ocorrido. Contudo, se é verdade que este deseja manter-se fiel aos fatos armazenados em sua memória, ao mesmo tempo ele está consciente de que jamais poderá realizar integralmente tal intento devido ao próprio caráter seletivo da memória, que acirra sua dúvida, ao invés de dissolvê-la. Além disso, a lacuna temporal que permeia os dois momentos, se de um lado estabelece certo distanciamento que lhe permite uma visão mais clara do passado, de outro mistura episódios antigos com recentes, situando tudo de maneira duvidosa. O protagonista não tem certeza de coisa nenhuma, como ele mesmo afirma num dado momento, não consegue nem mais distinguir os fatos em si de sua interpretação, do modo como ele os vê no presente; assim, a única forma que lhe parece viável de levar a cabo sua tarefa é representando tais fatos conforme se apresentam em sua mente, isto é, fragmentados, incompletos, em estado de busca.

Nesse momento, entretanto, surge um outro problema - o da expressão linguística propriamente - que se configura como uma das chaves não apenas da narrativa de Riobaldo, mas de toda a obra de Guimarães Rosa, e que pode resumir-se um pouco grosseiramente na pergunta: como representar um estado de dúvida, de busca, por meio de uma linguagem de certezas, desgastada e predominantemente referencial, como a que achamos ao nosso dispor? Riobaldo parece consciente de que sua visão de mundo atormentada, inflada na incerteza, só pode ser bem representada através de um discurso indagador, que procura e não aponta soluções, e é na busca de uma linguagem desta ordem, poética, criativa, efervescente - de uma linguagem, por que não dizer, também de busca, que brota límpida e fluida no momento mesmo da narração - que ele se lança em seu relato, estabelecendo uma relação isomórfica entre a sua Weltanschauung e a maneira de representá-la.

Este isomorfismo estabelecido entre a visão de mundo de Riobaldo e a linguagem usada para expressá-la, embora constitua, do ponto de vista estético, uma das grandes conquistas do romance de Guimarães Rosa, não abarca, contudo, nessa obra todo o processo de representação da realidade, que se complementa por um outro aspecto de importância similar - o fato de o protagonista representar seu estado de busca através da própria busca, isto é, da pesquisa que ele mesmo realiza de uma nova expressão linguística. Riobaldo usa a narração para efetuar a sua busca existencial, ou, em outras palavras, a própria narração se configura como um processo de busca; mas como tal processo só pode vir a realizar-se se ele encontra um tipo de 
linguagem específico (que indague mais do que afirme), verifica-se uma identificação entre os atos de viver e narrar, e sua busca existencial assume a forma da busca de uma nova expressão. Assim, além de representar sua visão de mundo através de um tipo de linguagem que, pelo seu caráter indagador, se presta mais adequadamente a esta função, o narrador cumpre a sua missão lançando mão de um recurso semelhante àquele que caracteriza a sua visão, e constrói o relato inteiro sob o signo da busca. É este último aspecto, fundamental para a compreensão de toda a obra, que se acha indicado pelos leitmotivs "Viver é muito perigoso" e "Contar é muito, muito dificultoso", repetidos com grande assiduidade através da narrativa.

A constituição de toda a narrativa do Grande sertão: veredas por meio de um processo de questionamento que instaura em todos os níveis a busca em seu sentido mais profundo, faz da obra algo vivo e dinâmico, em constante estado de fazer-se, que atua inevitavelmente sobre o leitor, induzindo-o à reflexão. E como é neste último dado que reside a base de qualquer transformação verdadeira, seja ela interior ou exterior ao próprio fenômeno da arte, o questionamento realizado nesse romance e, sob forma distinta, na obra rosiana como um todo, adquire um sentido ativo, amplamente comprometido, que o distingue tanto das obras de autores exclusivamente preocupados com o aspecto conteudístico, quanto dos puros experimentos formais, ambos tão comuns na narrativa contemporânea.

Os experimentos de Guimarães Rosa contêm traços que podem ser atribuídos às Vanguardas europeias do início do século XX, em especial ao Futurismo e ao Dadaísmo, no sentido da ruptura efetuada que faz de sua prosa, conforme afirmamos, um verdadeiro laboratório de reflexão, mas diferem fundamentalmente das propostas desses movimentos na recusa que estes clamam de toda a tradição passadista. O Modernismo brasileiro, já em sua fase heroica, inicial, da Geração de 1922, nunca endossou completamente esta visão, lançando, junto à apropriação efetuada de aspectos daquelas Vanguardas, um olhar crítico à tradição brasileira, máxime do período romântico, e tomando como imagem central do movimento a antropofagia dos Tupis, conforme expressa por Gonçalves Dias, em seu poema "I-Juca-Pirma". A Geração de 1945 retomou, é certo, muito da Geração de 1922, sobretudo a preocupação que devotou à reestruturação da linguagem, mas somou ao coloquialismo destes fortes tintas eruditas, que os aproximam talvez mais do Modernismo anglo-saxão de um Joyce. No entanto, mesmo reconhecendo semelhanças entre o autor do Ulysses e o nosso Rosa, há que assinalar-se que este último, a despeito da ruptura efetuada constantemete à norma, nunca chegou a ponto de infringir, como fez o dublinense, o sistema ou a estrutura mesma da língua portuguesa. E concluamos com a observação neste sentido do crítico Cavalcânti Proença:

Guimarães Rosa não faz outra coisa senão apelar para a consciência etimológica do leitor, neologizando vocábulos comuns, reavivando-lhes o significado (obliterado ou por demais esmaecido pelo uso corrente), dando-lhe uma precisão que esse mesmo uso acabou por destruir. Uma espécie de silêncio que desperta os moleiros quando cessa o rolar do moinho. (PROENÇA, 1958, p. 86) 


\section{Referências:}

ANDRADE, Oswald. “Manifesto Pau-Brasil”. In: TELES, Gilberto Mendonça, org. Vanguarda europeia e Modernismo brasileiro. 4ª ed. Petrópolis: Vozes, 1977.

COUTINHO, Eduardo F. Em busca da terceira margem: ensaios sobre o Grande sertão: veredas. Salvador: Fundação Casa de Jorge Amado, 1993.

. "Guimarães Rosa e o processo de revitalização da linguagem". In:

Guimarães Rosa. $2^{a}$ ed. Rio de Janeiro: Civilização Brasileira, 1991. Coleção "Fortuna Crítica" n. 6 .

LORENZ, Günter. "Diáogo com Guimarães Rosa”. In: COUTINHO, Eduardo F. (Org). Guimarães Rosa. $2^{a}$ ed. Rio de Janeiro: Civilização Brasileira, 1991. Coleção "Fortuna Crítica" n. 6.

PROENÇA, Manuel Cavalcânti. Trilhas no Grande sertão. Rio de Janeiro: Ministério da Educação e Cultura, 1958.

ROSA, João Guimarães. Grande sertão: veredas. $2^{\mathrm{a}}$ ed. Rio de Janeiro: José Olympio, 1958.

. Sagarana. $12^{\mathrm{a}}$ ed. Rio de Janeiro: José Olympio, 1970.

. Correspondência com seu tradutor italiano Edoardo Bizzarri. $2^{\mathrm{a}}$ ed. São Paulo: Instituto Italiano de Cultura, 1980. 